\title{
Towards an expert consensus to delineate a clinical syndrome of chronic breathlessness
}

\author{
Miriam J. Johnson ${ }^{1}$, Janelle Yorke ${ }^{2}$, John Hansen-Flaschen $\mathbb{1}^{3}$, Robert Lansing ${ }^{4}$, \\ Magnus Ekström ${ }^{5}$, Thomas Similowski ${ }^{6}$ and David C. Currow ${ }^{1,7}$
}

Affiliations: ${ }^{1}$ Hull York Medical School, University of Hull, Hull, UK. ${ }^{2}$ School of Nursing, Midwifery and Social Work, University of Manchester, Manchester, UK. ${ }^{3}$ Perelman School of Medicine, Hospital of the University of Pennsylvania, Philadelphia, PA, USA. ${ }^{4}$ Harvard Medical School, Beth Israel Hospital, Boston, MA, USA. ${ }^{5}$ Dept of Clinical Sciences, Division of Respiratory Medicine \& Allergology, Lund University, Lund, Sweden. ${ }^{6}$ Service de Pneumologie et Reanimation Medicale, Groupe Hospitalier Pitie-Salpetriere Charles Foix, Paris, France. ${ }^{7}$ University of Technology Sydney, Sydney, Australia.

Correspondence: Miriam J. Johnson, Hertford Building, Hull York Medical School, University of Hull, Hull, UK, HU6 7RX. E-mail: miriam.johnsonahyms.ac.uk

@ERSpublications

Chronic breathlessness syndrome: breathlessness and disability despite an optimally treated underlying pathophysiology http://ow.ly/V0g2309z4tF

Cite this article as: Johnson MJ, Yorke J, Hansen-Flaschen J, et al. Towards an expert consensus to delineate a clinical syndrome of chronic breathlessness. Eur Respir J 2017; 49: 1602277 [https://doi.org/ $10.1183 / 13993003.02277-2016]$.

ABSTRACT Breathlessness that persists despite treatment for the underlying conditions is debilitating. Identifying this discrete entity as a clinical syndrome should raise awareness amongst patients, clinicians, service providers, researchers and research funders.

Using the Delphi method, questions and statements were generated via expert group consultations and one-to-one interviews $(n=17)$. These were subsequently circulated in three survey rounds $(n=34, n=25$, $\mathrm{n}=31$ ) to an extended international group from various settings (clinical and laboratory; hospital, hospice and community) and working within the basic sciences and clinical specialties. The a priori target agreement for each question was $70 \%$. Findings were discussed at a multinational workshop.

The agreed term, chronic breathlessness syndrome, was defined as breathlessness that persists despite optimal treatment of the underlying pathophysiology and that results in disability. A stated duration was not needed for "chronic". Key terms for French and German translation were also discussed and the need for further consensus recognised, especially with regard to cultural and linguistic interpretation.

We propose criteria for chronic breathlessness syndrome. Recognition is an important first step to address the therapeutic nihilism that has pervaded this neglected symptom and could empower patients and caregivers, improve clinical care, focus research, and encourage wider uptake of available and emerging evidence-based interventions.

This article has supplementary material available from erj.ersjournals.com

Earn CME accreditation by answering questions about this article. You will find these at erj.ersjournals.com/journal/cme

Received: Sept 272016 | Accepted after revision: Feb 142017

Conflict of interest: Disclosures can be found alongside this article at erj.ersjournals.com

Copyright CERS 2017 


\section{Introduction}

Breathlessness as part of everyday living is one of the most common forms of distress, experienced by approximately $10 \%$ of the general population [1], with a worldwide prevalence that rivals that of pain [2]. Like pain, breathlessness can resist treatment of the identified underlying condition(s), but nonetheless can itself be a primary target of medical management, irrespective of the causative disease. In the case of pain, this situation is encompassed by the term "chronic pain syndrome" [3]. No comparable syndrome is identified for breathlessness. The question arises whether the experience of breathlessness persisting despite adequate treatment of causative conditions should be delineated as a syndrome.

A clinical syndrome (literally "a running together", from syn- "with" and dromos "a running, course" [4]) is a constellation of clinical findings caused by an underlying disease(s) that may or may not be accompanied by laboratory or imaging abnormalities. The clinical findings may constitute a range of symptoms and physical findings, or describe one symptom in a particular context(s), and may include the response to interventions targeted at the syndrome itself. The syndrome should be recognisable in clinical and research settings. Examples of clinical syndromes include delirium and chronic pain syndrome, acute respiratory distress syndrome, obstructive sleep apnoea syndrome and Tourette's.

Although difficult to prove "cause and effect", the description of a clinical syndrome appears to be associated with an increased awareness of its importance for clinicians, patients, service managers, commissioners, researchers and research funders. For example, since the delineation of chronic pain syndrome, many health services now have chronic pain clinics and there is an International Society for the Study of Pain with its journal Pain. This society has led the way in research into chronic pain, leading to a greater understanding of the mechanisms and management of chronic pain [3] that has allowed the development of effective interventions targeted at specific pathological process(es) or symptomatic treatment, as well as the development and validation of methods of assessing and measuring the effect of interventions.

A variety of chronic medical conditions cause breathlessness as a key symptom, including cardiorespiratory diseases, neuromuscular disorders, obesity, physical deconditioning, frailty and cancer (respiratory or not). It is also a feature of several conditions in which no somatic disorder can be identified, such as chronic hyperventilation syndrome and related entities. Algorithms to guide the investigation of breathlessness and to aid diagnosis and treatment of the underlying condition(s) are available, often leading to improvement of breathlessness [5]. However, despite optimal treatment of the underlying cause(s), breathlessness often persists at rest or on minimal exertion, worsening over time as the underlying cause(s) progresses [6, 7].

Breathlessness leads to serious limitations and distress for patients and their families, and negatively impacts on emotional function, with resulting low mood and poor quality of life often accompanied by episodes of more intense breathlessness and panic [8,9]. Activities that healthy people take for granted can become challenging for people who are chronically breathless. Clinicians may not recognise the impact of chronic breathlessness given that people experiencing this will most often adjust their lifestyle to minimise the frequency and duration of more intense breathlessness.

Chronic breathlessness is under-reported by patients and under-recognised by clinicians who focus on the underlying disease(s) or only see patients when acutely unwell. As such, it remains hidden from view [10], despite being an independent predictor of survival [11-14], restricted activities of daily living [12] and emergency health service use $[15,16]$. The importance of ongoing breathlessness as a symptom is still poorly recognised despite recent calls by researchers for this to be a research priority for people with chronic obstructive respiratory disease (COPD) [17] and for access to tailored management as a human right [18]

Currently, breathlessness that persists despite optimal treatment of the underlying conditions is sometimes referred to as "refractory breathlessness" or "refractory dyspnoea" [19, 20]. However, this terminology has not been the object of a formal definition and has never been formally proposed as a syndrome. Furthermore, the term refractory suggests complete resistance to treatment and therefore fails to convey a message of recognition in order to at least manage the symptoms; several interventions to reduce the symptom safely irrespective of its cause are available or under investigation [21-23]. Recognising breathlessness that persists in spite of optimal treatment as a clinical syndrome could be useful in the ways outlined above [24].

The aim of this study was to assess whether international expert consensus could be reached about 1) whether such breathlessness could and should constitute a clinical syndrome; and 2) if so, how this syndrome should be named and defined.

\section{Methods}

A three-stage process was employed. The first two stages were conducted in accordance with the Delphi method [25]. For stage 3, the results were presented and discussed during an international workshop. 
Stage 1: expert group consultations and single interviews

Internationally published experts in the field of breathlessness were identified and invited to contribute to a group or individual consultation by Skype or telephone conducted by DC and MJ $(n=17)$. Delegates were invited from the UK, continental Europe, USA and Australia to include a wide range of professional disciplines. Using snowball sampling, a non-probability sampling technique whereby existing participants recruit their own contacts to the study, invitees were asked to identify and invite other key opinion leaders.

A topic guide was used to ensure that each consultation included key areas but allowed other topics to arise. This followed a process of posing questions to generate ideas and debate, clarification and focus on areas of agreement, and then identification of the remaining areas of debate to be further explored during the survey rounds. The key areas included whether chronic breathlessness could and should constitute a clinical syndrome; if so, its name and definition; and the purpose that defining a syndrome would serve.

Detailed notes of agreements and disagreements were taken contemporaneously by MJ and DC, and used to identify those issues on which delegates agreed and those on which disagreement identified questions to use in the survey rounds.

\section{Stage 2: survey rounds}

A target $70 \%$ agreement for each question was pre-specified. Three sequential survey rounds (responses $\mathrm{n}=34, \mathrm{n}=25, \mathrm{n}=31$ ) were individually completed using an online platform (Qualtrics Insight Platform, Provo, UT, USA). The first survey (Invitation and Survey available as online-only text) was developed to explore views on a preliminary name and definition, as well as to answer specific questions relating to each concept within the definition. The survey was sent to an extended group of experts (the consultation group and others) by email $(\mathrm{n}=52)$ and was introduced with a summary of the prior iteration of agreement already reached during stage 1 . In addition to choosing their preferred option for each question, each participant was invited to generate additional views and clarifications as supplementary free text.

At the end of the first survey, respondents were asked if they were willing to participate in subsequent rounds. Those who agreed were sent surveys 2 and 3. Collated agreements circulated in successive rounds meant that responses were anonymous to other members of the group, reducing the risk that some may have felt pressure to conform to the views of others. Survey completion was taken as implied consent. As a result of each survey round, the name and definition were modified and options narrowed as consensus developed. As part of the last survey, a summary of the free text comments contributed by respondents was also provided.

\section{Stage 3: workshop}

The findings of the first two stages were presented and discussed at an international meeting for those interested in breathlessness research (Dyspnea 2016, Paris: www.dyspnea2016inparis.fr/). Specific discussions explored how such a name and definition would be translated usefully into different language and cultural settings.

Role of the funding source

This unfunded study was conducted within resources.

\section{Ethics}

Ethical approval was not required for the Delphi process because researchers sought expert professional opinions only.

\section{Findings}

\section{Group consultations and interviews}

Four group consultations comprising a total number of 13 participants $(n=5, n=4, n=2, n=2)$ were held between July 17th, and August 10th, 2015, each lasting approximately one hour. In addition, MJ interviewed four individuals. Invitees included experts in respiratory physiology and neuroimaging, and doctors and nurses from respiratory medicine, cardiovascular medicine, primary care, intensive care, oncology and palliative care.

There was agreement that the symptom of breathlessness in these clinical settings should be raised to a clinical syndrome in the context of 1) the persistence of breathlessness due to a causative medical condition(s) despite optimal treatment for the condition(s); and 2) negative consequences of the breathlessness.

It was agreed that recognition of a clinical syndrome would help to address the invisibility of such breathlessness. Further, for people experiencing this breathlessness, participants concurred that a recognised syndrome would help to validate their own experiences and give permission for patients to discuss their 
ongoing breathlessness with their clinicians. It was also felt that gaining research funding was rendered more difficult by a lack of recognition of chronic breathlessness by reviewers and research funders.

\section{Surveys}

The extended group also included occupational therapy and physiotherapy clinicians. The development of agreement can be seen in table 1 . All questions reached the pre-determined target of $\geqslant 70 \%$ agreement, except the part of the definition relating to how the treatment of the underlying disease should be phrased (68\%). All 35 respondents to survey 1 agreed to participate in surveys 2 and 3 . A summary of the free text comments provided to the respondents between surveys 2 and 3 can be seen in supplementary table S1.

\begin{tabular}{|c|c|c|c|c|c|c|}
\hline Respondents, $n$ & 35 & & 27 & & 31 & \\
\hline \multirow[t]{5}{*}{ Name of syndrome } & "chronic" & 67 & $\begin{array}{l}\text { Chronic } \\
\text { breathlessness }\end{array}$ & 26 & $\begin{array}{l}\text { Chronic } \\
\text { breathlessness }\end{array}$ & 77 \\
\hline & "refractory" & 58 & $\begin{array}{l}\text { Chronic persistent } \\
\text { breathlessness }\end{array}$ & 14 & & \\
\hline & "persistent" & 48 & & & & \\
\hline & "intractable" & 3 & & & & \\
\hline & "intolerable" & 3 & & & & \\
\hline \multicolumn{7}{|l|}{ Definition } \\
\hline Chronic & $\begin{array}{l}1 \text { month } / 3 \text { month/from } \\
\text { this point }\end{array}$ & 20 & & & & \\
\hline \multirow[t]{2}{*}{$\begin{array}{l}\text { Treatment of underlying } \\
\text { disease }\end{array}$} & $\begin{array}{l}\text { Treatment of } \\
\text { underlying medical } \\
\text { disease(s) is } \\
\text { optimised }\end{array}$ & 63 & $\begin{array}{l}\text { Treatment of } \\
\text { underlying } \\
\text { pathophysiology } \\
\text { is optimised }\end{array}$ & 41 & $\begin{array}{l}\text { Treatment of } \\
\text { underlying } \\
\text { pathophysiology is } \\
\text { optimised }\end{array}$ & 32 \\
\hline & $\begin{array}{l}\text { The underlying medical } \\
\text { disease(s) is } \\
\text { receiving best } \\
\text { possible treatment }\end{array}$ & 31 & $\begin{array}{l}\text { The patient is } \\
\text { receiving optimal } \\
\text { evidence-based } \\
\text { treatment for the } \\
\text { underlying } \\
\text { pathophysiology }\end{array}$ & 59 & $\begin{array}{l}\text { Evidence-based } \\
\text { treatment of } \\
\text { underlying } \\
\text { pathophysiology } \\
\text { is optimised }\end{array}$ & 68 \\
\hline \multirow{2}{*}{$\begin{array}{l}\text { Negative consequences } \\
\text { of breathlessness }\end{array}$} & Anxiety & 6 & $\begin{array}{l}\text { [breathlessness] } \\
\text { contributing to } \\
\text { physical } \\
\text { limitations }\end{array}$ & 3.7 & & \\
\hline & Deconditioning & 3 & & & & \\
\hline
\end{tabular}

Bold text indicates the questions reaching the pre-specified agreement threshold of $70 \%{ }^{\text {\# }}$ : see the survey in the supplementary material for details. 
The survey response rate was 34 out of $52(51 \%)$ for survey $1 ; 25$ out of 34 (74\%) for survey 2, and 31 out of 34 (91\%) for survey 3.

By survey 3, participants agreed that the name of the syndrome should be "chronic breathlessness syndrome" (77\%) and should be defined in the following way: breathlessness even though "...evidence-based treatments of underlying pathophysiology of the causative disease(s) are optimised" (68\%), "which contributes to physical limitations and/or a variety of adverse psychosocial, spiritual or other consequences" (77\%). The term "chronic" did not need a stated duration (80\%). Rather than continue to another round, $68 \%$ agreement for the treatment question was considered to be sufficient.

\section{Workshop}

Participants in the workshop agreed that chronic breathlessness should be defined as a clinical syndrome. It was suggested that the definition regarding the adverse consequences of chronic breathlessness should reflect the language of the World Health Organization (WHO) definition of disability to ensure global consistency [26]. The WHO International Classification of Functioning, Disability and Health (ICF) [26] defines disability as an overarching term for the interaction between individuals with a health condition (e.g. COPD) with personal and environmental factors (e.g. negative attitudes, inaccessible transportation and public buildings, or limited social supports).

There was extended and useful discussion about the transnational translation of the name and definition of the syndrome, particularly from the participants from the UK, Australia, France and USA. For example, the term "dyspnoea" was more familiar to US delegates, but it was recognised that the lay term "breathlessness" should be used. The other contender was "short of breath", but, on balance, it was felt that the addition of "chronic" made it clear that the syndrome referred to troublesome breathlessness. German attendees felt that no additional words to define breathlessness were needed; "refractory" would be unhelpful in German, giving the sense of "no hope", and "short of breath" had a particular meaning that was inappropriate. For Swedish participants, "chronic breathlessness" was deemed to be "acceptable". The French participants felt that an adjective was needed, with the term "persistante" in addition to, or in place of, "chronic". Although the English speakers felt that "chronic" implicitly contained the notion of "pathological", this was not the case for French speakers. There was concern about the term "dyspnée" because the lay term "essoufflement" (exact French translation of "breathlessness") encompasses both worrying and non-worrying situations (as in being "out of breath" - essoufflé - after acute exertion). However, "essoufflement persistant" or "essoufflement chronique persistant" could be discussed.

It was decided that the Dyspnea working group of the French learned society for respiratory medicine (Société de Pneumologie de Langue Française) could secondarily conduct a specific project aimed at providing the best French translation of "chronic breathlessness syndrome".

It is hoped that this start towards some international consensus will stimulate further debate and discussion, including translation into other languages and cultures.

\section{Discussion}

Using the Delphi method enhanced by an extended discussion among participants at an international meeting of experts on breathlessness, we attained broad consensus on the utility of recognising a distinct clinical entity that can be named "chronic breathlessness syndrome". We define this syndrome as the experience of breathlessness that persists despite optimal treatment of the underlying pathophysiology and results in disability for the patient. Participants decided that a descriptor such as "refractory" was not needed (and, indeed, was considered unhelpful by some) in the title or in the definition.

A pathophysiological basis is not required in order to delineate a clinical syndrome. However, there is emerging evidence suggesting that the perception of chronic breathlessness in patients and acute breathlessness induced in healthy volunteers differs in some respects although they share common pathways. Neuroimaging studies indicate that people living with chronic breathlessness may have a higher level of breathlessness "vigilance" even when comfortably at rest compared with healthy volunteers [27]. The central perception of chronic breathlessness due to COPD involves activation of the frontal associative cortex (fear and memory) that is not seen in healthy volunteers [28]. Further, people with COPD have a higher neural respiratory drive at rest than healthy volunteers [29,30]. Neural respiratory drive closely correlates with breathlessness intensity and has been suggested as a biomarker for chronic breathlessness [30].

The personal, behavioural and social adjustments in patients with chronic breathlessness are clearly of a different kind and order than in those experiencing acute, episodic breathlessness. In addition, the clinically important difference for breathlessness intensity is smaller for chronic breathlessness (a 1 point change on a 0-10 numerical rating scale, compared with a 2 point change for acute breathlessness) [20, 31]. The experiences are different, and thus benefit is likely to be perceived differently. An improvement of 2 points 
may be needed to reassure the distressed, terrified person with acute, episodic breathlessness that they are not going to die. Conversely, an improvement of 1 point for the person living with chronic breathlessness as a daily limitation may mean that they are then able to make their own cup of tea, or manage to get to the toilet on their own.

\section{Implications for clinical practice and policy}

Widespread opinion from a variety of specialties and professions was sought so that the proposed definition, with its common language, would be broadly relevant across research methods and clinical practices as well as to patients living with chronic medical conditions leading to chronic breathlessness. Whereas it is good clinical practice to seek out and assess a symptom systematically, this is not routine in many settings in which the focus is on optimising the underlying disease treatments. Systematic documentation of chronic breathlessness in healthcare settings alone is unlikely to be sufficient to alter practice in the context described here, and from work in pain, assessment alone is unlikely to improve symptom control [32]. The delineation of chronic breathlessness syndrome provides focus for directed systematic clinical enquiry, including targeted intervention. Usual practice often stops at the point of optimised treatment of the underlying disease(s) ("nothing more we can do"). However, there are non-pharmacological and pharmacological evidence-based interventions for chronic breathlessness as a therapeutic target [21, 23, 33-37], but these remain underused in clinical practice. Routine assessment will increasingly help to standardise the timely use of these treatments and foster a robust multi-disciplinary team approach whereby patients are referred routinely for active management of breathlessness by respiratory physiotherapists and psychologists and considered systematically for regular, low-dose oral extended-release morphine. We cannot guarantee that the recognition of this syndrome will change clinical practice and clinical outcomes; however, without its recognition we will not see progress and patients will not derive the benefit they deserve.

Education about these interventions is crucial because clinicians may be reluctant to look for something they believe they cannot treat. With regards to service provision, the identification of chronic breathlessness syndrome may result in evidence-based breathlessness services becoming the standard of care. Multi-disciplinary and multi-speciality breathlessness services are already developing (e.g. pulmonary and cardiology), albeit with a focus on diagnosis. A next step could be for such specialised clinics to expand their scope to research and practice of breathlessness palliation.

Although much of the literature relating to the management of the symptom of breathlessness has come from palliative care to date, this clinical presentation is seen in family medicine/general practice, respiratory medicine, cardiology, geriatrics and palliative care. Therefore, the responsibility to address chronic breathlessness syndrome is one that must be shared by the medical community as a whole.

The overt recognition of chronic breathlessness syndrome will empower patients and their caregivers to more easily raise their symptom burden in clinical consultations, rather than suffering in silence. Likewise, ensuring that the community is more broadly aware of the syndrome will facilitate conversations to drive better care.

The syndrome of chronic pain provides a useful parallel in some aspects. Recognition that chronic pain is a different entity to acute pain and thus should be managed differently [3] was pivotal in improving the understanding, management and service provision of this common and difficult condition. The devastating impact on psychosocial function and the resultant disability, often caught up in a deteriorating cycle of unhelpful adaptation to the symptom by reducing activity, is common to both. An understanding of this has informed the multi-disciplinary nature of chronic pain clinics, with an emphasis on physiotherapy and psychological approaches to management, and appears pertinent to chronic breathlessness. Likewise, the more recently proposed clinical entity "dyspnea crisis" [38] is highly pertinent to this discussion in that crises often occur on a background of chronic breathlessness. There are notable differences, however, in that chronic pain syndrome includes a plethora of subtypes described in a complex taxonomy [39], and, unlike severe breathlessness, the experience of chronic pain is rarely associated with a fear of imminent death.

There may be concerns that recognising chronic breathlessness as a syndrome may lead to inappropriate and excessive prescribing of opioids, particularly for patients who may be vulnerable to overdose, such as patients with advanced COPD $[34,40]$. We suggest that a formally delineated chronic breathlessness syndrome would stimulate a posology of opioid prescription based on evidence-based effectiveness and safety data rather than the current variations in practices, including inadequately evaluated regimens. This would allow greater net benefit and place pharmacological treatment within a step-wise approach to management founded on non-pharmacological management [41].

\section{Implications for research}

Chronic breathlessness syndrome will create a common language between and within groups of researchers. More consistent descriptions of study populations will help the application of findings. A distinct entity that 
stimulates a structured and mechanistic approach should also help target research priorities towards gaining a further understanding of the pathophysiology of chronic breathlessness and towards identifying further potential therapeutic targets and optimal service delivery models. Recognition of chronic breathlessness syndrome could also create a profile for potential funders.

Importantly, the involvement of patients and family caregivers in the development of consensus can now be addressed given the frame that this initial work provides.

\section{Strengths and limitations}

This paper deliberately sought the views of opinion leaders, i.e members of the community of clinicians and researchers who are influential not because they have opinions, but because their opinions are sought after and published. The opinions of this wide range of respondents from around the world were successfully synthesised into a definition that could be used in a number of other languages. This definition spans people working in the basic sciences as well as a variety of clinical specialities.

The limitations are those that are inherent to the Delphi processes. Not all respondents completed all surveys, but the response rate for surveys 2 and 3 was good. There was no clear pattern in the non-respondents in the first survey. Given the broad nature of the professional background of participants, a slightly lower a priori agreement threshold of $70 \%$ was set. However, one question failed to reach this, although most achieved higher agreement than the more typical threshold agreement of $75 \%$. There may be concerns that a Delphi method is open to bias towards inclusion of only like-minded experts. However, there was vigorous debate throughout the survey rounds, nearly requiring a fourth survey. Further, the Paris Dyspnea 2016 workshop was not part of the Delphi process. It was attended by people who were independent from it and who were unaware that this would be on the agenda in this manner; they were not hand-picked.

Inherent with the methodology, the number of participants is limited. Therefore, the respondents' views cannot be fully representative of all concerned. We expect that this proposition of chronic breathlessness syndrome will generate reactions and debate, and we acknowledge that this term may evolve as a result. Linguistic and cultural specificities may lead to variations around the world and there may be further discussion on how the chosen terminology applies to certain clinical situations. For example, a participant in the Dyspnea 2016 workshop noted that "breathlessness that persists in spite of optimal treatment of the underlying conditions" is frequently experienced by critically ill patients receiving prolonged mechanical ventilation [42]. However, in this setting, the word "chronic" may not be relevant to intensivists to characterise the corresponding category of patients, and could be replaced by "persistent". The very fact that questions and debates will arise in reaction to the present proposition should be considered as a first marker of its relevance.

\section{Conclusions}

We propose chronic breathlessness syndrome as a framework for further discussion. Whatever the name (or names) finally agreed upon and recognised globally, such recognition of a distinct clinical syndrome is likely to improve clinical care, focus research and, ultimately, reduce suffering by empowering patients and their caregivers. Additional development is warranted, including the engagement of patients and family caregivers to refine understanding and application. Using the syndrome as the basis for a wider use of evidence-based interventions is an important first step to address the therapeutic nihilism that has pervaded this area of practice.

\section{Acknowledgements}

We thank the participants for giving their time and expertise to this project. MJ had full access to all of the data in the study and takes responsibility for the integrity of the data and the accuracy of the data analysis.

\section{References}

1 Currow DC, Plummer JL, Crockett A, et al. A community population survey of prevalence and severity of dyspnea in adults. J Pain Symptom Manage 2009; 38: 533-545.

Harstall C, Ospina M. How prevalent is chronic pain? Pain Clin Upd 2003; 11: 1-4.

Addison RG. Chronic pain syndrome. Am J Med 1984; 77: 54-58.

Harper D. Online etymology dictionary. www.etymonline.com Date last accessed: November 13, 2016.

Pratter MR, Abouzgheib W, Akers S, et al. An algorithmic approach to chronic dyspnea. Respir Med 2011; 105: 1014-1021.

6 Currow DC, Smith J, Davidson PM, et al. Do the trajectories of dyspnea differ in prevalence and intensity by diagnosis at the end of life? A consecutive cohort study. J Pain Symptom Manage 2010; 39: 680-690.

7 Ahmadi Z, Lundstrom S, Janson C, et al. End-of-life care in oxygen-dependent COPD and cancer: a national population-based study. Eur Respir J 2015; 46: 1190-1193.

8 Booth S, Silvester S, Todd C. Breathlessness in cancer and chronic obstructive pulmonary disease: using a qualitative approach to describe the experience of patients and carers. Palliat Support Care 2003; 1: 337-344.

9 Disler RT, Green A, Luckett T, et al. Experience of advanced chronic obstructive pulmonary disease: metasynthesis of qualitative research. J Pain Symptom Manage 2014; 48: 1182-1199. 
10 Gysels M, Higginson IJ. Access to services for patients with chronic obstructive pulmonary disease: the invisibility of breathlessness. J Pain Symptom Manage 2008; 36: 451-460.

11 Nishimura K, Izumi T, Tsukino M, et al. Dyspnea is a better predictor of 5-year survival than airway obstruction in patients with COPD. Chest 2002; 121: 1434-1440.

12 Smith A, Currow DC, Abernethy AP, et al. Prevalence and outcomes of breathlessness in older adults: a national population study. J Am Geriatr Soc 2016; 64: 2035-2041.

13 Hammond EC. Some preliminary findings on physical complaints from a prospective study of 1,064,004 men and women. Am J Public Health Nations Health 1964; 54: 11-23.

14 Waller K, Kaprio J, Kujala UM. Dyspnea and all-cause mortality: 28-yr follow-up study among adult twins. Med Sci Sports Exerc 2014; 46: 1538-1545.

15 Niska R, Bhuiya F, Xu J. National Hospital Ambulatory Medical Care Survey: 2007 emergency department summary. Natl Health Stat Report 2010; 1-31.

16 Langlo NM, Orvik $\mathrm{AB}$, Dale J, et al. The acute sick and injured patients: an overview of the emergency department patient population at a Norwegian University Hospital Emergency Department. Eur J Emerg Med 2014; 21: 175-180.

17 Currow DC, Abernethy AP, Allcroft P, et al. The need to research refractory breathlessness. Eur Respir J 2016; 47: 342-343.

18 Currow DC, Abernethy AP, Ko DN. The active identification and management of chronic refractory breathlessness is a human right. Thorax 2014; 69: 393-394.

19 Booth S, Bausewein C, Higginson I, et al. Pharmacological treatment of refractory breathlessness. Expert Rev Respir Med 2009; 3: 21-36.

20 Johnson MJ, Bland JM, Oxberry SG, et al. Clinically important differences in the intensity of chronic refractory breathlessness. J Pain Symptom Manage 2013; 46: 957-963.

21 Ekstrom M, Nilsson F, Abernethy AA, et al. Effects of opioids on breathlessness and exercise capacity in chronic obstructive pulmonary disease. A systematic review. Ann Am Thorac Soc 2015; 12: 1079-1092.

22 Ekstrom MP, Abernethy AP, Currow DC. The management of chronic breathlessness in patients with advanced and terminal illness. BMJ 2015; 349: g7617.

23 Higginson IJ, Bausewein C, Reilly CC, et al. An integrated palliative and respiratory care service for patients with advanced disease and refractory breathlessness: a randomised controlled trial. Lancet Respir Med 2014; 2: 979-987.

24 Johnson MJ, Currow DC. Chronic refractory breathlessness is a distinct clinical syndrome. Curr Opin Support Palliat Care 2015; 9: 203-205.

25 Hsu C, Sandford BB. The Delphi technique: making sense of consensus. Pract Assess Res Eval 2007; 12: 1-8.

26 WHO. International Classification of Functioning, Disability and Health (ICF): Towards a Common Language for Functioning, Disability and Health. Geneva, World Health Organization, 2002.

27 Johnson MJ, Simpson MI, Currow DC, et al. Magnetoencephalography to investigate central perception of exercise-induced breathlessness in people with chronic lung disease: a feasibility pilot. BMJ Open 2015; 5: e007535.

28 Herigstad M, Hayen A, Evans E, et al. Dyspnea-related cues engage the prefrontal cortex: evidence from functional brain imaging in COPD. Chest 2015; 148: 953-961.

29 Jolley CJ, Luo YM, Steier J, et al. Neural respiratory drive in healthy subjects and in COPD. Eur Respir J 2009; 33 289-297.

30 Jolley CJ, Luo YM, Steier J, et al. Neural respiratory drive and breathlessness in COPD. Eur Respir J 2015; 45: 355-364.

31 Karras DJ, Sammon ME, Terregino CA, et al. Clinically meaningful changes in quantitative measures of asthma severity. Acad Emerg Med 2000; 7: 327-334.

32 Bennett MI, Flemming K, Closs SJ. Education in cancer pain management. Curr Opin Support Palliat Care 2011; 5: $20-24$.

33 Currow DC, McDonald C, Oaten S, et al. Once-daily opioids for chronic dyspnea: a dose increment and pharmacovigilance study. J Pain Symptom Manage 2011; 42: 388-399.

34 Ekstrom MP, Bornefalk-Hermansson A, Abernethy AP, et al. Safety of benzodiazepines and opioids in very severe respiratory disease: national prospective study. BMJ 2014; 348: g445.

35 Farquhar MC, Prevost A, McCrone $\mathrm{P}$, et al. Is a specialist breathlessness service more effective and cost-effective for patients with advanced cancer and their carers than standard care? Findings of a mixed-method randomised controlled trial. BMC Med 2014; 12: 194.

36 Johnson MJ, Kanaan M, Richardson G, et al. A randomised controlled trial of three or one breathing technique training sessions for breathlessness in people with malignant lung disease. BMC Med 2015; 13: 213.

37 Livermore N, Dimitri A, Sharpe L, et al. Cognitive behaviour therapy reduces dyspnoea ratings in patients with chronic obstructive pulmonary disease (COPD). Respir Physiol Neurobiol 2015; 216: 35-42.

38 Mularski RA, Reinke LF, Carrieri-Kohlman V, et al. An official American Thoracic Society workshop report: assessment and palliative management of dyspnea crisis. Ann Am Thorac Soc 2013; 10: S98-S106.

39 Task Force on Taxonomy of the International Association for the Study of Pain. Classification of Chronic Pain. Descriptions of Chronic Pain Syndromes And Definitions Of Pain Terms. 2nd Edition. Seattle, IASP Press, 1994.

40 Vozoris NT, Wang X, Fischer HD, et al. Incident opioid drug use among older adults with chronic obstructive pulmonary disease: a population-based cohort study. Br J Clin Pharmacol 2016; 81: 161-170.

41 Rocker GM, Sinuff T, Horton R, et al. Advanced chronic obstructive pulmonary disease: innovative approaches to palliation. J Palliat Med 2007; 10: 783-797.

42 Schmidt M, Banzett RB, Raux M, et al. Unrecognized suffering in the ICU: addressing dyspnea in mechanically ventilated patients. Intensive Care Med 2014; 40: 1-10. 